\title{
Synergistic Effects of Conjugation and Polarization on Dual Amide Hydrogen-bonding in $\mathrm{CCl}_{4}$ : Theory and Experiment
}

\author{
Shannon G. Lieb ${ }^{1, *}$, Paula LeBlanc ${ }^{2}$ \\ ${ }^{1}$ Emeritus, Butler University, 4600 Sunset Avenue, Indianapolis, United States \\ ${ }^{2}$ Department of Anesthesia, Baylor College of Medicine, United States
}

Copyright $(2018$ by authors, all rights reserved. Authors agree that this article remains permanently open access under the terms of the Creative Commons Attribution License 4.0 International License

\begin{abstract}
The doubly hydrogen-bonded dimer of pyrrolidinone ( $\gamma$-lactam) is used as a benchmark for the effect of conjugation on the strength and extent of hydrogen-bonding of the compounds Oxindole and Isoxindole. The experimental portion of this project consists of collecting the FTIR spectrum of $\gamma$-lactam, Oxindole and Isoxindole in $\mathrm{CCl}_{4}$. The concentrations and temperatures were varied to determine the thermodynamic properties of $\Delta \mathrm{H}_{\mathrm{d}}, \Delta \mathrm{S}_{\mathrm{d}}$ and $\mathrm{K}_{\mathrm{d}}$. In addition, the spectroscopic parameters of the difference of the monomer and dimer $\mathrm{N}-\mathrm{H}$ stretching frequencies $(\Delta v)$ and the ratio of the molar extinction coefficients of the dimer and monomer $\left(\varepsilon_{\mathrm{d}} / \varepsilon_{\mathrm{m}}\right)$ are experimentally determined. The values of $\Delta \mathrm{H}_{\mathrm{d}}$, $\Delta \mathrm{S}_{\mathrm{d}}, \Delta v$ and $\varepsilon_{\mathrm{d}} / \varepsilon_{\mathrm{m}}$ are computed using MP2 and B3LYP methods with $6-31 \mathrm{G}^{* *}$ and $6-31+\mathrm{G}^{* *}$ basis sets. The experimental values are best described by B3LYP/6-31G**with the incorporation of the dielectric effect $(\mathrm{PCM})$ of $\mathrm{CCl}_{4}$. The experimental and computational results support the results of increased or decreased hydrogen-bond strength due to conjugation effects on the polarization of the monomers in forming dimers.
\end{abstract}

Keywords Hydrogen-bonding, Lactams, Conjugation Effects, Electrostatic Potential, Equilibrium Constants

\section{Introduction}

\subsection{Historical Background}

At the turn of the $20^{\text {th }}$ century, the famous architect, John Sullivan [1], used the concept of "Form Follows Function" as a basic principle in creating the modern architectural structure the skyscraper. Since the advent of quantum chemistry, molecular architecture has recognized the reverse phrasing of "Function Follows Form". Linus
Pauling's [2] book entitled The Nature of the Chemical Bond related the importance of intra and intermolecular forces that leads to a deeper understanding of the form and function of molecules. In particular, his work and the work of Watson and Crick led to understanding the form of protein and DNA structure from a quantum theoretical perspective. The helical structure of proteins and the double helical structure of DNA obtained by X-ray diffraction of their crystal structures were determined to be the product of multiple hydrogen-bonding. The importance of hydrogen-bonding is fundamental in understanding self-assembling structures in biochemistry [3].

\subsection{Explanation of Terminology}

Peter Politzer, et. al. [4] have clarified the difference between covalent and noncovalent bonding using the Hellmann-Feynman theorem. Terms such as exchange, Pauli repulsion, correlation, orbitals, etc. are mathematical models having no connection to experimental observables. These mathematical models are essential to the development of the computation of electrostatic potential maps, which are directly related to observable electrostatic potential through diffraction methods [5]. The electro-static maps are the computed electrostatic interactions of the atoms in the molecule. The electrostatic maps of the hydrogen-bonded dimers (i.e., non-covalent interactions) reveals the electron density shift (polarization) in the individual monomers of the hydrogen-bonded dimer.

\section{Objectives}

The primary focus of this paper is to study the effect of conjugation on cyclic amide dimer formation relative to the saturated ring structure of 2-pyrrolindinone ( $\gamma$-lactam). The experimental results of this study demonstrate that 
conjugation with the amide carbonyl has an enhancing effect on the strength and extent of hydrogen-bonding relative to the saturated lactam and that conjugation with the amide lone pair reduces the strength and extent of hydrogen-bonding with respect to the saturated lactam. To that end, saturated lactams are a logical connection to the importance of hydrogen-bonding in proteins and conjugation introduced into the lactam ring is a logical connection to the conjugation found in DNA bases. Based on our previous work [6] and the work of others $[7,8,9,10,11,12]$ in the study of the thermodynamic properties of lactams in non-polar solvents, there are three logical compounds for this study: $\gamma$-lactam, $\gamma$-lactam-3ene and $\gamma$-lactam-4-ene (Figures $1 \mathrm{a}, 1 \mathrm{~b}$ and $1 \mathrm{c}$, respectively).

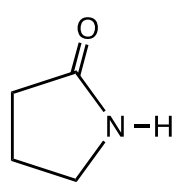

a) $\gamma$-lactam

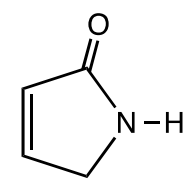

b) $\gamma$-lactam-3-ene

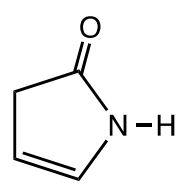

c) $\gamma$-lactam-4-ene
Figure 1. Three compounds used in a theoretical study the effect of conjugation on the lactam portion of $\gamma$-lactam.

However, the synthesis of either of these two geometric isomers results in a 9:1 ratio, respectively, at room temperature [13], making thermodynamic property determination infeasible. To circumvent the isomerization problem, two other compounds, Oxindole and Isoxindole, have been used in this recent work. These two extended conjugated lactams; Oxindole and Isoxindole are shown in Figure 2. Only one study of the dimer equilibrium of Oxindole[14] in $\mathrm{CCl}_{4}$ was found to compare with this work.<smiles>O=C1Cc2ccccc2N1</smiles>

a) Oxindole

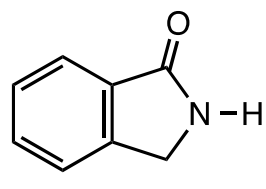

b) Isoxindole
Figure 2. The two conjugated lactam structures used in the experimental and theoretical studies of the effect of conjugation on $\gamma$-lactam (Figure 1a).

Guillaumes and Simon [15] carried out a theoretical study of 16 compounds including the three compounds in Figure $1 \mathrm{a}$ ), b) and c). That study dealt with quasi-ring formation of amide structures that were similar to DNA base pairs. Their paper delved into the topic of how much assistance is obtained through $\pi$ bond delocalization. This resonance assistance is referred to as Resonance-Assisted Hydrogen-Bonding (RAHB) and is a part of an active debate $[16,17,18,19,20,21]$ among many research groups. The RAHB is the creation of the Double Hydrogen-Bond Dimer (DHBD). In contrast to the RAHB, our experimental results indicate that the intramolecular interactions of the two monomer units results in the enhancement of $\mathrm{HB}$ formation.

The first aspect in understanding the effects of conjugation with the amide portion of the lactam is the experimental determination of enthalpy, entropy and the equilibrium constant of HB formation for $\gamma$-lactam, Oxindole and Isoxindole (see Figure 2). The saturated lactam, $\gamma$-lactam (Figure 1a), is a five membered ring, which has an intramolecular resonance between the carbonyl group and the nitrogen of the lactam ring. The saturated lactam is the benchmark in this study for the effect of conjugation introduced in two positions of the lactam ring.

Computation of the spectral peak positions and extinction coefficients of the monomer and dimer $\mathrm{N}-\mathrm{H}$ and $\mathrm{C}-\mathrm{H}$ stretching modes gave credence to the experimental spectral peak assignments as well as the ratio of total absorption of the monomer and dimer bands. The calculated enthalpy, entropy of dimerization with and without the effect of the dielectric effect of $\mathrm{CCl}_{4}$ introduced by the Polarizable Continuum Model (PCM) provided detailed molecular structure effects that enhanced the understanding to the experimental results.

\section{Experimental Details}

The compounds for this study were purchased from Aldrich with $98-99 \%$ purity. The saturated lactams are known to be quite hydroscopic. In order to dry and remove any impurities in $\gamma$-lactam, it was recrystallized from dry ether and suction filtered under a blanket of ultra high purity dry nitrogen. The dry Oxindole and Isoxindole crystals were slightly gray in color. To remove any potential impurities, the crystals were purified to very white crystals by an overnight vacuum sublimation at approximately $80^{\circ} \mathrm{C}$. Stock solutions of all three lactams were prepared in $\mathrm{CCl}_{4}$ and checked for water contamination by looking in the area of 1 to $1.5 \mathrm{ppm}$ of their NMR spectra.

The spectra of $\gamma$-lactam, Oxindole and Isoxindole were obtained using a Perkin Elmer, Spectrum One, Fourier transform infrared (FTIR) spectrometer. The sample chamber was kept moisture free by constant purging with ultra high purity dry nitrogen. The sample cell made by Starna Cells, Inc. is a one mm path length Infrasil ${ }^{\circledR}$ cell with a circulating water jacket to control the temperature of the solution. The exit temperature of the Infrasil ${ }^{\circledR}$ cell was determined by placing a digital thermometer in a glass cell filled with water. The glass cell had the exit water passing through its own water jacket. The equilibrium constants $\left(\mathrm{K}_{\mathrm{d}}\right)$ of all three compounds were determined at the temperatures of $6.4^{\circ} \mathrm{C}, 15.9^{\circ} \mathrm{C}, 25.4^{\circ} \mathrm{C}$ and $34.9^{\circ} \mathrm{C}$. A cylindrical cell holder was constructed to hold the Infrasil ${ }^{\circledR}$ sample cell and also block the absorption of IR light that would occur from passing through the heating/cooling 
jacket.

The cutoff frequency on the low end of the sample cell is approximately $2500 \mathrm{~cm}^{-1}$. The range of our investigation is between 2500 to $3500 \mathrm{~cm}^{-1}$. The carbonyl peak for the lactam and indoles is $\sim 1700 \mathrm{~cm}^{-1}$ and therefore outside the range of this experimental setup.

The solutions for all three lactams were prepared by successive dilutions from a stock solution. There were thirteen solutions for $\gamma$-lactam prepared in the range of $0.08 \mathrm{M}$ to $0.006 \mathrm{M}$ with the range of absorbances for the dimer in the range of 1.0 (highest concentration and lowest temperature) to 0.05 . Six solutions for Oxindole were prepared in the range of $0.05 \mathrm{M}$ to $0.005 \mathrm{M}$ concentrations with corresponding absorbances ranging from 0.6 to 0.03 . Because of the low solubility of Isoxindole, the six $\mathrm{CCl}_{4}$ solution concentrations were prepared in the range from $0.006 \mathrm{M}$ to $0.0006 \mathrm{M}$. The absorbances for the peak maximum of the Isoxindole dimer were in the range of 0.5 to 0.04.All experimental results whether this research group or others are for comparison to our computed results.

\section{Computational Details}

\subsection{Quantum Chemical Calculations}

The computational portions of this research were conducted either with the Gaussian Inc. 03[21] suite using the Hartree Fock, MP2 and B3LYP methods, and 6-31G** and $6-31+\mathrm{G}^{* *}$ basis sets or GAMESS [22]. The Gaussian Inc. 03 implementation of the PCM to model the effect of the non-polar solvent dielectric of $\mathrm{CCl}_{4}$ is also employed in all calculations for comparison to our experimental results.

For the comparison to previous research involving Resonance Assisted Hydrogen-Bonding (RAHB) calculations, our research used GAMESS and its implementation of the B3LYPV3 method with the 6-311++ $\mathrm{G}^{* *}$ basis set. The B3LYPV3 method in GAMESS was found to give comparable results to the B3LYP method of G03.

All frequency calculations were based on geometry optimized structures using the same method and basis set.

\subsection{Computational Analysis of Experimental Data}

The determination of the dimer formation equilibrium constant, $\mathrm{K}_{\mathrm{d}}$, is computed by the following derivation. The areas under the dimer and monomer peak are directly proportional to the concentration of individual chemical species according to Beer's Law. The molar extinction coefficients of the monomer and dimer, $\varepsilon_{m}$ and $\varepsilon_{d}$, are the integrated values of the absorbance bands in order to compare to the computed values of the line intensities to the experimental IR band areas.

$$
A_{m}=\varepsilon_{m} b C_{m} \text { and } A_{d}=\varepsilon_{d} b C_{d}
$$

(1a \& 1b)
The subscripts $m$ and $d$ stand for monomer and dimer, respectively and the capital $\mathrm{A}, \varepsilon, \mathrm{b}$ and $\mathrm{C}_{\mathrm{T}}$ stand for the total band absorbance (area under the peak), the molar extinction coefficient, the cell path length and the total solution concentration, respectively. The dimer equilibrium constant is written as:

$$
K_{d}=\frac{C_{d}}{C_{m}^{2}}=\frac{C_{T}-C_{m}}{2 C_{m}^{2}}
$$

Putting this equation into quadratic form and solving for $\mathrm{C}_{\mathrm{m}}$ in terms of in terms of $\mathrm{K}_{\mathrm{d}}$ and $\mathrm{C}_{\mathrm{T}}$ leads to the equation:

$$
C_{m}=\frac{-1+\sqrt{1+8 K_{d} C_{T}}}{4 K_{d}}
$$

Rewriting $\mathrm{K}_{\mathrm{d}}$ in terms of equation 1 , one obtains the following equation:

$$
K_{d}=\frac{C_{d}}{C_{m}^{2}}=\frac{A_{d} \varepsilon_{m}}{A_{m} \varepsilon_{d}} \frac{1}{C_{m}}
$$

Rearranging equation 4 and incorporating equation 3 yields the following equation:

$$
\frac{A_{d}}{A_{m}}=\frac{1}{4} \frac{\varepsilon_{d}}{\varepsilon_{m}}\left(-1+\sqrt{1+8 K_{d} C_{T}}\right)
$$

Equation 5 is evaluated by the non-linear, Simplex, algorithm, which minimizes the sum of the squares of the residuals between the calculated absorbance ratio as a function of the total concentration, $\mathrm{C}_{\mathrm{T}}$, by adjusting the parameters $\varepsilon_{\mathrm{d}} / \varepsilon_{\mathrm{m}}$ and $\mathrm{K}_{\mathrm{d}}$. The values for the $\varepsilon_{\mathrm{d}} / \varepsilon_{\mathrm{m}}$ ratio and $\mathrm{K}_{\mathrm{d}}$ are computed for each of the four temperatures. The average of epsilon ratios for each compound is used to re-compute $K_{d}$ at each temperature and then the van't Hoff equation (equation 6) is used to evaluate $\Delta \mathrm{H}_{\mathrm{d}}$ and $\Delta \mathrm{S}_{\mathrm{d}}$.

$$
\ln \left(K_{d, T}\right)=-\frac{\Delta H_{d}}{R} \frac{1}{T}+\frac{\Delta S_{d}}{R}
$$

\section{Results and Interpretation}

\subsection{Sample Spectra and Assignments}

The typical spectra of $\gamma$-lactam, Oxindole and Isoxindole are presented in Figures 3, 4 and 5, respectively. All of the aromatic and aliphatic $\mathrm{C}-\mathrm{H}$ stretches show up in the range of $2800-3000 \mathrm{~cm}^{-1}$. The $\mathrm{N}-\mathrm{H}$ stretching frequencies of the dimer and monomer peaks are indicated in each figure. The vertical line at the dimer peak maximum and moving to higher frequencies is the region whose area is to be determined. The dimer peak maximum at $\sim 3200 \mathrm{~cm}^{-1}$ is overlapped on the lower frequency side, but is relatively smooth and consistent with a Lorentzian spectral line shape. The total area under the curve including half of the dimer 
and all of the monomer peaks are determined as indicated in the Figures 3, 4 and 5. Once the monomer peak area is baseline corrected and the area computed, the dimer area equals twice the difference of between the total area minus the monomer peak area.

Representative spectra of the three compounds in this study are shown in Figures 3 through 5 . The peaks between those marked as $\mathrm{C}-\mathrm{H}$ stretches and the assigned dimer peak are common features in the spectra of all concentrations of all three compounds. $\mathrm{A} \mathrm{CCl}_{4}$ solution of $\gamma$ lactam-d6 with the amide $\mathrm{N}-\mathrm{H}$ bond left intact revealed that the deuterated $\gamma$ lactam peaks that are assigned as $\mathrm{C}-\mathrm{H}$ disappeared and left the other peaks unchanged (see Figure 6). The shifted $\mathrm{C}-\mathrm{D}$ frequencies are thereby used to assign the $\mathrm{C}-\mathrm{H}$ frequencies. The experimentally assigned $\mathrm{C}-\mathrm{H}$ stretches compared to the computed $\mathrm{C}-\mathrm{H}$ stretches showed that B3LYP/6-31G** along with PCM produced the best correlation between experiment and computation.

The tables 1a through 1c are constructed to validate the scaling of the calculated frequencies versus the assigned experimental frequencies. The graphical presentations of the linear regression accompanying the peaks are presented in Figures 7 through 9. Typically, a multiplicative scaling factor [23] is applied to the computed frequencies to produce better agreement between computed and experimental frequencies. In these experiments, since there are either four or five of the experimental frequencies attributable to $\mathrm{C}-\mathrm{H}$ normal mode frequencies, the simultaneous scaling of the $\mathrm{C}-\mathrm{H}$ and $\mathrm{N}-\mathrm{H}$ monomer and dimer frequencies becomes a feasible approach to verifying the correlation between experiment and theoretical prediction. The best overall comparison between theory and experiment for $\Delta v, \varepsilon_{\mathrm{d}} / \varepsilon_{\mathrm{m}}, \Delta \mathrm{H}_{\mathrm{d}}$ is the B3LYP/6-31G** method/basis with the dielectric effect of $\mathrm{CCl}_{4}$ introduced using PCM as implemented by Gaussian 03.

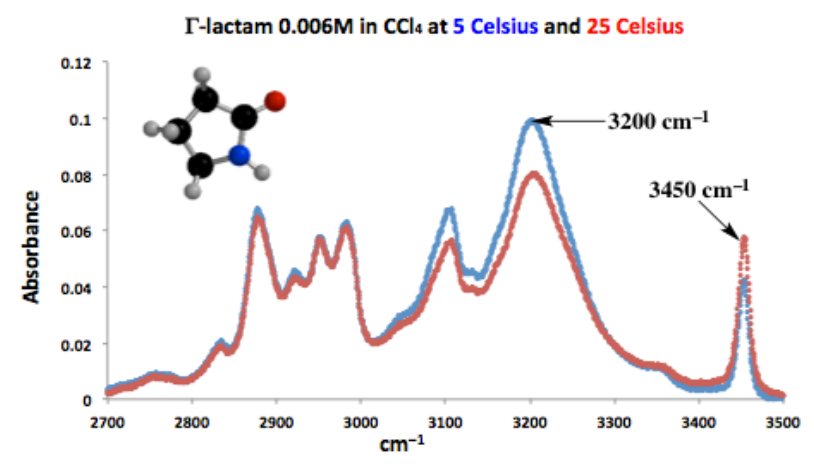

Figure 3. Representative FTIR Spectrum for $\gamma$-lactam in CCl4
All experimental data sets of peak positions for the monomer and dimer $\mathrm{N}-\mathrm{H}$ frequencies and the set of $\mathrm{C}-\mathrm{H}$ frequencies for each compound are assigned by performing a linear regression between the experimental and calculated frequencies. The best $\mathrm{R}^{2}$ value determined the experimental assignments seen in Tables 1a - c. The slope and intercept of the regression analysis determined the scaling of the computed frequencies. The slopes are greater than unity because the intercept is no longer assumed to be zero as it is by the normal convention [23] for scaling of infrared frequencies.

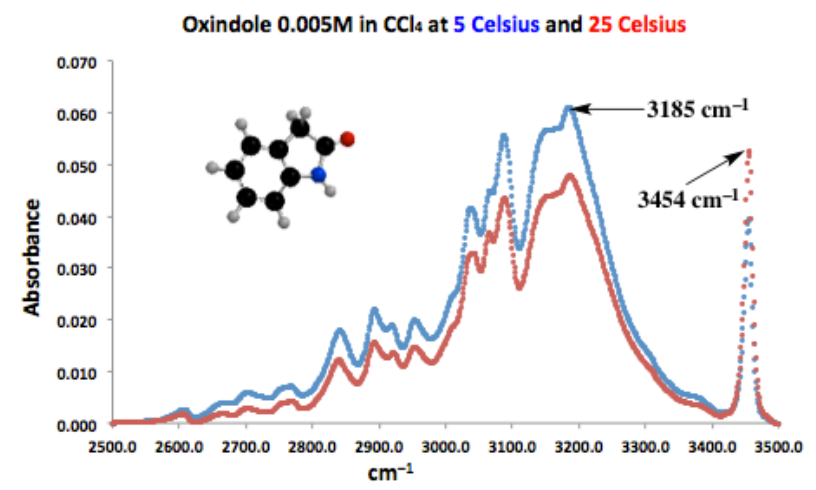

Figure 4. Representative FTIR Spectrum for Oxindole in $\mathrm{CCl}_{4}$

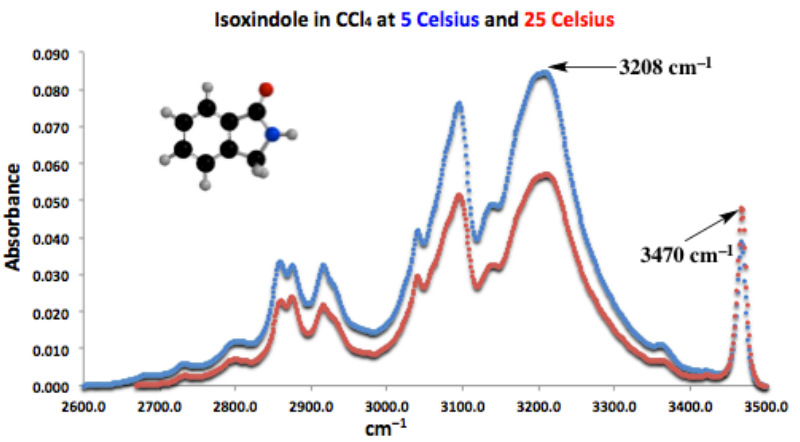

Figure 5. Representative FTIR Spectrum for Isoxindole in $\mathrm{CCl}_{4}$

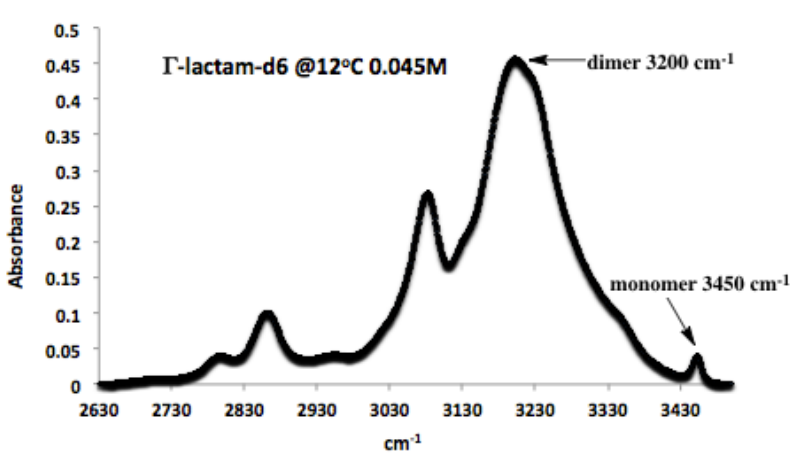

Figure 6. Representative FTIR spectrum of $\Gamma$-lactam-d6 in $\mathrm{CCl}_{4}$

\subsection{Spectral Line Analysis}


Table 1a. Linear regression scaling $\Gamma$-lactam frequencies (B3LYP/6-31G**//PCM $\left(\mathrm{CCl}_{4}\right)$ )

\begin{tabular}{|c|c|c|c|}
\hline Assignment & Computed $\left(\mathrm{cm}^{-1}\right)$ & Observed $\left(\mathrm{cm}^{-1}\right)$ & 3457 \\
\hline N-H monomer & 3556 & 3450 & 3194 \\
\hline N-H dimer & 3321 & 3200 & 2980 \\
\hline C-H & 3130 & & 2971 \\
\hline C-H & 3122 & 2980 & 2930 \\
\hline C-H & 3085 & 2950 & 2912 \\
\hline C-H & 3069 & 2920 & 2895 \\
\hline C-H & 3054 & 2875 & 2846 \\
\hline C-H & 3010 & 2830 & \\
\hline
\end{tabular}

Table 1b. Linear regression scaling Oxindole frequencies (B3LYP/6-31G**//PCM $\left(\mathrm{CCl}_{4}\right)$ )

\begin{tabular}{|c|c|c|c|}
\hline Assignment & Computed $\left(\mathrm{cm}^{-1}\right)$ & Observed $\left(\mathrm{cm}^{-1}\right)$ & 3467 \\
\hline N-H monomer & 3550 & 3454 & 3140 \\
\hline N-H dimer & 3297 & 3185 & 3005 \\
\hline C-H aromatic & 3192 & & 2993 \\
\hline C-H aromatic & 3183 & 3033 & 2979 \\
\hline C-H aromatic & 3172 & 2948 & 2971 \\
\hline C-H aromatic & 3166 & 2914 & 2878 \\
\hline C-H & 3094 & 2892 & 2831 \\
\hline C-H & 3057 & 2834 & \\
\hline
\end{tabular}

Table 1c. Linear regression scaling Isoxindole frequencies (B3LYP/6-31G**//PCM $\left(\mathrm{CCl}_{4}\right)$ )

\begin{tabular}{|c|c|c|c|}
\hline Assignment & Computed $\left(\mathrm{cm}^{-1}\right)$ & Observed $\left(\mathrm{cm}^{-1}\right)$ & 3458 \\
\hline N-H monomer & 3575 & 3468 & 3168 \\
\hline N-H dimer & 3322 & 3208 & 3140 \\
\hline C-H aromatic & 3192 & & 2993 \\
\hline C-H aromatic & 3183 & 2939 & 2997 \\
\hline C-H aromatic & 3173 & 2923 & 2987 \\
\hline C-H aromatic & 3164 & 2880 & 2852 \\
\hline C-H & 3046 & 2863 & 2818 \\
\hline C-H & 3017 & & \\
\hline
\end{tabular}

\subsection{Peak Assignments by Others}

Other peak assignments made by previous investigators of $\gamma$-lactam and Oxindole[6,7,8,9,24] are consistent with this method. The research by Pandy, et., al.,[25,26] had the specific objective of assigning the peaks for single hydrogen bonded dimers (SHBD) and double hydrogen bonded dimers (DHBD) of $\gamma$-lactam and $\delta$-lactam. His research group performed matrix isolation-FTIR spectra in a solid $\mathrm{N}_{2}$ matrix at $8 \mathrm{~K}$ and a $\mathrm{CCl}_{4}$ solution FTIR spectra in the temperature range of $30^{\circ}$ to $45^{\circ} \mathrm{C}$. Their findings revealed that the SHBD peak at the $v_{\mathrm{C}=0}$ 'isosbestic point' established that there were two components in equilibrium, i.e., the most natural choices being the monomer and DHBD. In addition, the band found in the $\mathrm{CCl}_{4}$ solution $v_{\mathrm{N}}$ н $\sim 3200 \mathrm{~cm}^{-1}$ is attributed to the DHBD as well. Their calculations using B3PW91/6-311++G** are highly correlated to their experimentally assigned spectral bands. A very small peak between the assigned monomer and dimer peaks was a transient peak in the $\mathrm{CCl}_{4}$ solution for $\gamma$-lactam. The $\delta$-lactam $\mathrm{CCl}_{4}$ solution had a persistent peak, which was assigned to a SHBD peak. In our studies, that intermediate peak persisted in all of the $\gamma$-lactam solutions as well as the Oxindole and Isoxindole $\mathrm{CCl}_{4}$ solutions. Careful inspection of all three of our example spectra reveals this minor peak in the $3350-3400 \mathrm{~cm}^{-1}$ range and is consistent with a SHBD peak. The inclusion and exclusion of this minor peak made no change in the computed equilibrium constants.

\subsection{Thermodynamic/Spectral Experimental and Computational Analysis}


The van't Hoff plots of $\ln \left(\mathrm{K}_{\mathrm{d}}\right)$ versus the inverse of the Kelvin temperature gave the results on Table 2 for the enthalpy and entropy changes associated with dimer formation. The $\mathrm{R}^{2}$ values were at least 0.997 .

Hartree-Fock calculations were performed, but gave the least agreement between theory and experiment. The scaled computed spectral lines as shown in Tables $1 \mathrm{a}, 1 \mathrm{~b}$ and $1 \mathrm{c}$ are not used in computing $\Delta v$ 's in Table 2 . Just the raw computed frequencies are placed in Table 4 along with their computed intensity ratios, $\varepsilon_{\mathrm{d}} / \varepsilon_{\mathrm{m}}$. The best computed estimates of $\Delta v, \varepsilon_{\mathrm{d}} / \varepsilon_{\mathrm{m}}$ and $\Delta \mathrm{H}_{\mathrm{d}}$ are found in the columns, which employed PCM. Although a few of the absolute values for $\Delta v, \varepsilon_{\mathrm{d}} / \varepsilon_{\mathrm{m}}$ and $\Delta \mathrm{H}_{\mathrm{d}}$ are better determined by the B3LYP/6-31+G** PCM combination, the trends of these three values are correctly determined by B3LYP/6-31+G**//PCM calculations. As expected, the $\mathrm{R}^{2}$ value for the linear regression between the B3LYP/6-31G**//PCM computed and the experimental values for $\Delta v, \varepsilon_{\mathrm{d}} / \varepsilon_{\mathrm{m}}$ and $\Delta \mathrm{H}_{\mathrm{d}}$ proved to be superior to the B3LYP/6-31+G** PCM linear regression.

The computed entropy change for dimerization for all methods fell in the range of -36 to $-39 \mathrm{~J} / \mathrm{mol}-\mathrm{K}$. The large discrepancy between the calculated and the experimentally determined value is most likely due to the solvent reorganization entropy that accommodates the introduction of the solute molecules. Applying a thermodynamic cycle in which the entropy change for the monomer solute molecule moving into the gas phase followed by the entropy change for dimer formation in the gas phase and finally the entropy change accompanying the re-introduction of the dimer solute molecule back into the solvent, would be equal to the entropy change for solute monomer molecules forming a solute dimer (see Figure 7)

The thermodynamic cycle in Figure 7 illustrates the difference in the entropy changes for solvating two monomers and a dimer, $\Lambda S_{d, m}$. Using the computed entropy change in the column headed ${ }^{\mathrm{b}} \mathrm{B} 3 \mathrm{LYP} / \mathrm{PCM}$, yields a $\Delta \Delta \mathrm{S}_{\mathrm{d}, \mathrm{m}}=94.6 \mathrm{~J} / \mathrm{mol}-\mathrm{K}$ for $\gamma$-lactam, $105.0 \mathrm{~J} / \mathrm{mol}-\mathrm{K}$ for Oxindole and $76.6 \mathrm{~J} / \mathrm{mole}-\mathrm{K}$ for Isoxindole. Once the entropy changes are accounted for by the $\Delta \Delta \mathrm{S}_{\mathrm{d}, \mathrm{m}}$, the parallel trend between the strength of the $\mathrm{HB}$ as measured by $\Delta \mathrm{H}_{\mathrm{d}}$ and the magnitudes of the equilibrium constants unfold.

Table 2. Computed values of various methods and basis sets versus the experimental values

\begin{tabular}{|c|c|c|c|c|c|c|c|}
\hline & ${ }^{\mathrm{a}} \mathrm{MP2}$ & 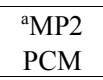 & ${ }^{\mathrm{a} B 3 L Y P}$ & $\begin{array}{c}{ }^{\mathrm{a} B 3 L Y P} \\
\text { PCM }\end{array}$ & ${ }^{\mathrm{b}} \mathrm{B} 3 \mathrm{LYP}$ & $\begin{array}{c}{ }^{\mathrm{b} B} 3 \mathrm{LYP} \\
\text { PCM }\end{array}$ & Expt'l \\
\hline \multicolumn{8}{|l|}{$\gamma$-lactam } \\
\hline$\Delta v\left(\mathrm{~cm}^{-1}\right)$ & 287.7 & 252.6 & 330.0 & 235.0 & 315.4 & 204.6 & 244 \\
\hline$\varepsilon_{\mathrm{d}} / \varepsilon_{\mathrm{m}}$ & 42.7 & 20.0 & 72.3 & 27.3 & 56.8 & 21.9 & 20.4 \\
\hline$\Delta \mathrm{H}_{\mathrm{d}}(\mathrm{kJ} / \mathrm{mol})$ & -69.75 & -49.29 & -67.15 & -45.77 & -53.22 & -28.5 & -29.8 \\
\hline$\Delta \mathrm{S}_{\mathrm{d}}(\mathrm{J} / \mathrm{mol}-\mathrm{K})$ & -155.8 & -166.0 & -155.2 & -153.1 & -155.9 & -153.9 & -59.37 \\
\hline$K_{d} @ 25.0^{\circ} \mathrm{C}$ & & & & & & & 133 \\
\hline \multicolumn{8}{|l|}{ Oxindole } \\
\hline$\Delta v\left(\mathrm{~cm}^{-1}\right)$ & 322.3 & 203.7 & 354.8 & 252.6 & 340.6 & 223.5 & 269 \\
\hline$\varepsilon_{\mathrm{d}} / \varepsilon_{\mathrm{m}}$ & 39.8 & 18.6 & 59.5 & 25.5 & 52.4 & 22.2 & 25.3 \\
\hline$\Delta \mathrm{H}_{\mathrm{d}}(\mathrm{kJ} / \mathrm{mol})$ & -73.05 & -54.46 & -68.16 & -45.35 & -55.56 & -29.49 & -25.5 \\
\hline$\Delta \mathrm{S}_{\mathrm{d}}(\mathrm{J} / \mathrm{mol}-\mathrm{K})$ & -155.4 & -153.9 & -160.1 & -156.1 & -161.0 & -162.8 & -57.66 \\
\hline$K_{d} @ 25.0^{\circ} \mathrm{C}$ & & & & & & & 111 \\
\hline \multicolumn{8}{|l|}{ Isoxindole } \\
\hline$\Delta v\left(\mathrm{~cm}^{-1}\right)$ & 321.1 & 220.6 & 359.6 & 252.1 & 343.3 & 232.0 & 257 \\
\hline$\varepsilon_{\mathrm{d}} / \varepsilon_{\mathrm{m}}$ & 40.0 & 18.6 & 61.6 & 24.9 & 51.3 & 21.1 & 24.4 \\
\hline$\Delta \mathrm{H}_{\mathrm{d}}(\mathrm{kJ} / \mathrm{mol})$ & -73.18 & -51.67 & -69.08 & -47.03 & -56.11 & -30.75 & -36.6 \\
\hline$\Delta \mathrm{S}_{\mathrm{d}}(\mathrm{J} / \mathrm{mol}-\mathrm{K})$ & -163.8 & -154.3 & -160.4 & -155.4 & -160.4 & -156.2 & -79.5 \\
\hline$K_{d} @ 25.0^{\circ} \mathrm{C}$ & & & & & & & 179 \\
\hline
\end{tabular}

${ }^{\mathrm{a}}$ basis set is $6-31 \mathrm{G}^{* *}$; ${ }^{\mathrm{b}}$ basis set is $6-31+\mathrm{G}^{* *}$ 


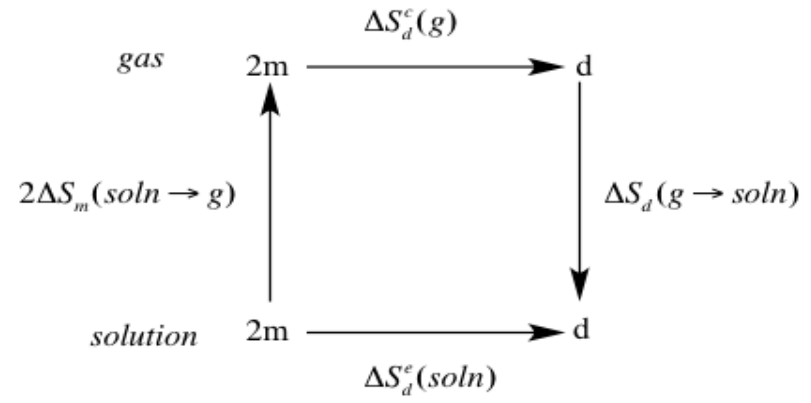

Figure 7. The thermodynamic cycle relating entropy changes for the experimental and computed entropies of dimerization.

The $\Delta \Delta \mathrm{S}_{\mathrm{d}, \mathrm{m}}$ referred to above is defined by the equations 7 and 8 , which follow:

$$
\begin{gathered}
\Delta S_{d}^{e}(\operatorname{soln})=S_{d}^{e}(\text { soln })-2 S_{m}^{e}(\text { soln })= \\
\Delta S_{d}^{e}(\text { soln })=S_{d}^{e}(\text { soln })-2 S_{m}^{e}(\text { soln })= \\
\Delta S_{d}^{e}(\operatorname{soln})-\Delta S_{d}^{c}(\mathrm{~g})=\Delta S_{d}(g \rightarrow \text { soln })- \\
\Delta S_{d}^{e}(\operatorname{soln})-\Delta S_{d}^{e}(\mathrm{~g})=\Delta S_{d}(g \rightarrow \text { soln })-
\end{gathered}
$$

The ratio of molar extinction coefficients, $\varepsilon_{\mathrm{d}} / \varepsilon_{\mathrm{m}}$, are reduced by a factor of $40 \%$ to $70 \%$ reduction for the MP2 and B3LYP methods using either basis set when the solvent dielectric effect is introduced by the PCM model. The reduction in the $\varepsilon_{\mathrm{d}} / \varepsilon_{\mathrm{m}}$ ratio is due primarily to the enhancement of $\varepsilon_{\mathrm{m}}$. The Self Consistent Reaction Field (SCRF) as simulated by PCM creates an electron redistribution of the solute electron density, which in turn enhances the dipole moment of the monomer and $\varepsilon_{\mathrm{m}}$. Since the dimer formation shields the polar ends of the molecules from the influence of the electric field of the dielectric medium, the $\varepsilon_{\mathrm{d}}$ do not change significantly with PCM turned on.

\subsection{Comparison to Other Research}

As a comparison of our results to others, Table 3 was created. Thermodynamic properties of $\gamma$-lactam in $\mathrm{CCl}_{4}$ have been an object of research predating 1969. Only one IR project for Oxindole [14] in $\mathrm{CCl}_{4}$ was uncovered in our literature search. Several references $[4,5,7,8]$ dating from 1969 are used for comparison to our findings. All of these research groups used an extrapolation to zero concentration to determine the $\varepsilon_{\mathrm{m}}$ for the Beer's Law equation relating absorbance to the concentration of $\mathrm{C}_{\mathrm{m}}$. Three of the research groups [4,5,7] use three different linear relationships between $A_{m}$ and $C_{T}$ to evaluate $K_{d}$. The Prokopenko, et. al.[8] research group used the Levenberg-Marquart nonlinear method to extract the $\mathrm{K}_{d}$ from the nonlinear equation, dependent on the monomer $\mathrm{N}-\mathrm{H}$ stretching frequency.

Neither Kirkorian nor Walmsley performed a temperature dependence of their $\mathrm{K}_{\mathrm{d}}$, which precludes a comparison of the other thermodynamic functions. However, Walmsley's research did indicate the presence of a small amount of $\gamma$-lactam trimer at high concentrations in $\mathrm{CCl}_{4}$. All researchers referenced in Table 3 assigned the peak $\sim 3200 \mathrm{~cm}^{-1}$ to the DHBD form of $\gamma$-lactam.

Koll, et. al.,[14] research group did not perform a temperature study of $\mathrm{K}_{\mathrm{d}}$ for Oxindole in $\mathrm{CCl}_{4}$. Their IR spectral features and band assignments are consistent with our research. The determination of $\mathrm{K}_{\mathrm{d}}$ for Oxindole was determined using dipole moment measurements as a function of concentration in $\mathrm{CCl}_{4}$ as described in the article. In turn, these spectral features and assignment of IR bands are consistent with Flakus, et. al.,[27] research group. Flakus' research includes the X-ray structure and the polycrystalline $\mathrm{KBr}$ pellet IR spectrum of Oxindole. The IR pellet spectrum is compared to a $\mathrm{CCl}_{4}$ solution at $293 \mathrm{~K}$ to establish the assignment of the IR bands in $\mathrm{CCl}_{4}$. The very different experimental techniques in measuring the dimer and monomer concentrations by Koll, et. al.,

\begin{tabular}{|c|c|c|c|c|}
\hline Compound & $\begin{array}{l}\text { Research } \\
\text { group }\end{array}$ & $\begin{array}{l}K_{d} @ \\
25^{\circ} \mathrm{C} \\
\end{array}$ & $\begin{array}{c}\Delta \mathbf{H}_{\mathrm{d}} \\
(\mathrm{kJ} / \mathrm{mol})\end{array}$ & $\begin{array}{c}\Delta S_{d} \\
(J / m o l-K) \\
\end{array}$ \\
\hline \multicolumn{5}{|l|}{$\gamma$-lactam } \\
\hline & Krikorian $^{a}$ & $\begin{array}{c}147 \\
\text { (a) } 21^{\circ} \mathrm{C} \\
\end{array}$ & - & - \\
\hline & Walmsley $^{\mathrm{b}}$ & 118 & - & - \\
\hline & Chen $^{\mathrm{c}}$, et. al. & 184 & -26.7 & -44.4 \\
\hline & $\begin{array}{c}\text { Prokopenko }^{\mathrm{d}}, \\
\text { et. al. }\end{array}$ & 246 & -22.0 & -28.0 \\
\hline & This group & 134 & -29.3 & -59.4 \\
\hline \multicolumn{5}{|l|}{ Oxindole } \\
\hline & Kolle, et. al. & 380 & - & - \\
\hline & This group & 113 & -28.9 & -57.7 \\
\hline
\end{tabular}
accounts for their relatively large $\mathrm{K}_{\mathrm{d}}$ value relative to ours.

Table 3. Thermodynamic parameters for $\gamma$-lactam and Oxindole - IR with $\mathrm{CCl}_{4}$ solvent

${ }^{\mathrm{a}}$ reference $8 .,{ }^{\mathrm{b}}$ reference $6 .,{ }^{\mathrm{c}}$ reference $5 .,{ }^{\mathrm{d}}$ reference $9 .,{ }^{\mathrm{e}}$ reference 12 .

The experimental X-ray and IR data compared to the computed values are shown in Table 4. Crystal structures for $\gamma$-lactam [28] and Oxindole [29] are the only discovered structures found by this research group. In the case of Oxindole, the dimer does not retain the $\mathrm{C}_{2}$ symmetry found in the calculations. The two crystallographic independent monomer units have their bond lengths in parenthesis. The comparison of the structural parameters determined by B3LYP/6-31G** with PCM to the X-ray structure is used because that computational method/basis gives the best trends in the thermodynamic and spectroscopic calculations in comparison to the other experimental results shown on Table 2. The calculated values of the $\varepsilon_{\mathrm{m}}$ and $\varepsilon_{\mathrm{d}}$ in units of $\mathrm{km} / \mathrm{mol}$ are listed on Table 4 , so that their ratio can be compared to the experimental ratio, $\varepsilon_{\mathrm{d}} / \varepsilon_{\mathrm{m}}$.

\subsection{Resonance Assisted Hydrogen-Bonding versus Polarization}

Another objective of this project is to determine the 
effect of conjugation with the resonance already inherent in the lactam structure. The saturated lactam, $\gamma$-lactam, serves as a benchmark for the effect of electron delocalization that is incurred by the conjugation with the carbonyl group or the amide nitrogen. Presently, there are ongoing investigations into the area of RAHB and the contribution (if any) to the strengthening hydrogen-bonds in molecules such as DNA. This question has been approached from several different perspectives with varying results. One approach is to try to assess the amount of electron delocalization via a pseudo $\pi$-resonance created by the ring-like structure of DHBD.

A conclusion reached by Palusiak, et. al. [17,18,19], is that there is a good correlation between the additional stabilization found in intramolecular RAHB and delocalization indices. The delocalization indices quantify the strength between proton and proton acceptor interactions.

Beck and Mo [30] provide another interpretation of hydrogen-bond strength in which the primary effect of multiple hydrogen-bonding is attributed to enhanced dipole-dipole interactions of the monomers. Sanz and co-workers [31] have also found that electron density in $\pi$-type orbitals do not contribute significantly to extra stabilization that has been attributed to RAHB. The electrostatic model of amide DHBD is also supported by Gilli and Gilli [32]. In their analysis of $\mathrm{N}-\mathrm{H}---\mathrm{O} \mathrm{HB}$ strength and the amount of covalency of the HB, the deciding factor is the N...O distance between the two monomers in the DHBD. According to the analysis of hundreds of crystal structures, the strongly hydrogen-bonded amides had N...O distances $\leq 2.66 \AA$. Distances further than that are predominately electrostatic in nature. According to our calculations and the crystal structure data included in Table 4, the N...O distances are > $2.8 \AA$. In the conclusions of Guerra, et. al.[33], "... regarding the intrinsic cohesion of DNA, we may conclude that it is the chemical charge-transfer nature of the hydrogen bond in Watson-Crick base pairs, rather than resonance assistance by the $\pi$-electron system, that together with the classical electrostatic interaction is vital to the behavior and the stability and, thus, the evolution of nature's genetic code."

Guillaumes and Simon [15] have done their own analysis of the cooperativity of DHBD delocalization indices to answer the question of intramolecular RAHB by computing the energetic contribution of each $\mathrm{HB}$ in a DHBD. Their study involves thirteen compounds incorporating multiple HB when dimerized. These include formamide through 5 and 6 membered rings of varying amounts of conjugation and numbers of HB sites. Their comparison of correlations between pairwise and n-centered delocalization indices, and the interaction energy, $E_{\text {int, }}$ and inter-ring interaction energy, $E_{R i R}$, indicates that the stabilization of a quasi-ring DHBD is dominated by electron reorganization within the individual fragments of the dimer.

$$
\begin{gathered}
E_{\text {int }}=E_{D H B D}-2 E_{m} \\
E_{\text {RiR }}=E_{\text {int }}-E_{H B 1}-90^{\circ}-E_{H B 2}-90^{\circ}
\end{gathered}
$$

Table 4. Comparison of B3LYP/6-31G** with PCM (CC14) optimized geometries and frequencies vs. experimental values (CCl4) of monomer and

\begin{tabular}{|c|c|c|c|c|c|c|}
\hline & actam & & Oxind & & Isoxin & ole \\
\hline Parameter & Calc & Expt & Calc & Expt & Calc & Expt \\
\hline Monomer & & & & & & \\
\hline $\mathrm{N}-\mathrm{H}\left(\mathrm{cm}^{-1}\right)$ & 3556 & 3452 & 3550 & 3455 & 3575 & 3468 \\
\hline $\mathrm{N}-\mathrm{H}(\mathrm{km} / \mathrm{mol})$ & 78.84 & & 116.3 & & 135.79 & \\
\hline $\mathrm{N}-\mathrm{H} \quad \AA$ & 1.014 & & 1.015 & & 1.013 & \\
\hline $\mathrm{C}=\mathrm{O} \quad \AA$ & 1.224 & & 1.219 & & 1.226 & \\
\hline $\mathrm{C}-\mathrm{N} \quad \AA$ & 1.366 & & 1.382 & & 1.375 & \\
\hline Dimer (C2 sym & hetry) & & & & & \\
\hline $\mathrm{N}-\mathrm{H}\left(\mathrm{cm}^{-1}\right)$ & 3321 & 3208 & 3297 & 3186 & 3322 & 3211 \\
\hline $\mathrm{N}-\mathrm{H}(\mathrm{km} / \mathrm{mol})$ & 2151 & & 2962 & & 3376 & \\
\hline $\mathrm{N}-\mathrm{H} \quad \AA$ & 1.029 & & 1.030 & & 1.029 & \\
\hline $\mathrm{C}=\mathrm{O}$ & 1.239 & $1.232 \mathrm{a}$ & 1.234 & $(1.234,1.233)^{\mathrm{b}}$ & 1.241 & \\
\hline $\mathrm{C}-\mathrm{N}$ & 1.349 & $1.335 \mathrm{a}$ & 1.365 & $(1.354,1.342)^{b}$ & 1.358 & \\
\hline N...O $\AA$ & & & & & & \\
\hline
\end{tabular}
dimer lactams 
The quasi-ring formation of formamide is shown in Figure 8a. The disruption of the quasi-ring structure is shown in Figure 8b. This structure of a Single Hydrogen-Bonded Dimer is created by a rigid rotation of the monomer units by $90^{\circ}\left(\right.$ SHBD- $\left.90^{\circ}\right)$ about one of the HBs

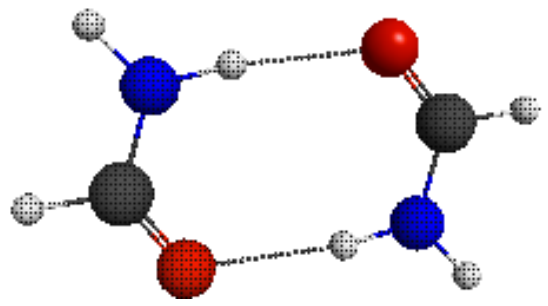

Figure 8a. DHBD

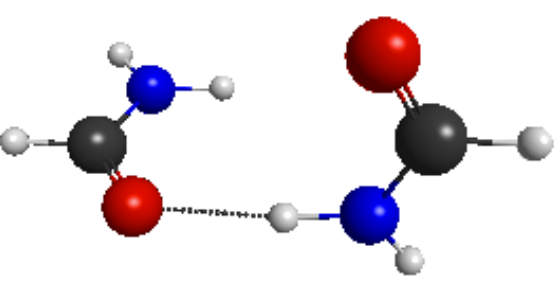

Figure 8b. SHBD- $90^{\circ}$

Within each monomer unit in the Guillaumes and Simon study, each monomer has both a proton donor and acceptor. Three of the molecules in their study were $\gamma$-lactam, $\gamma$-lactam-3-ene and $\gamma$-lactam-4-ene (see Figures 1). By comparison, their conclusions reinforce the interpretation of our calculations based on electron redistribution within the monomer fragments of $\gamma$-lactam, Oxindole and Isoxindole hydrogen-bonded dimer of our study.

The Guillaumes and Simon $E_{R i R}$ values were determined by a modification of the Asensio[34] method as defined in equation 10. The Guillaumes and Simon group used Gaussian 03 and the DFT method and basis set B3LYP/6-311++G**. We have used the GAMESS DFT method and basis set B3LYPV3/6-311++G**. The DHBD geometries of Guillaumes and Simon were fully optimized, but their SHBD- $90^{\circ}$ calculations were based on the optimized DHBD with only a torsional rotation around one HB set to $90^{\circ}$. The $90^{\circ}$ configuration is a transition state of a full DHBD to a SHBD- $180^{\circ}$ configuration, as evidenced by the imaginary frequency associated with this calculation.
In Table 5, our results for the SHBD- $180^{\circ}$ s are fully optimized geometries represented in Figures $9 \mathrm{a}$ and $9 \mathrm{~b}$. The primary difference in these two dimer geometries is that the $\gamma$-lactam-3-ene (and its mimic, Isoxindole) is essentially planar with the unbound carbonyl oxygen hydrogen-bonded to the $\mathrm{C}-\mathrm{H}$ proton in the 3 position and the $\gamma$-lactam-4-ene (and its mimic, Oxindole) is twisted out of planarity due to the hydrogen-bonding to one of the two $\mathrm{C}-\mathrm{H}$ protons in the 3 position. The saturated $\gamma$-lactam has the same twisting as shown in Figure 10b. The computed $\Delta \mathrm{H}_{\mathrm{d}}$ trends are the same for the DHBD and SHBD with the enthalpies of both of the conjugated HB compounds being stronger than the saturated $\gamma$-lactam.

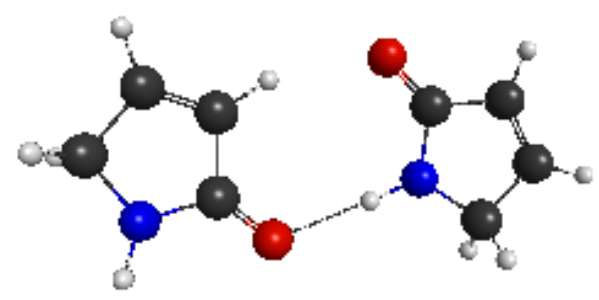

Figure 9a. lactam-3-ene SHBD-180

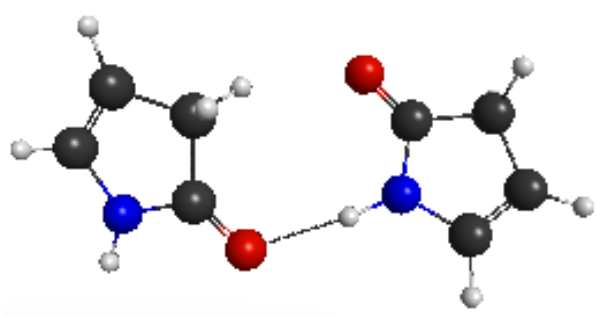

Figure 9b $\cdot \gamma$-lactam-4-ene SHBD-180

For consistency with the Guillaumes and Simon paper, the values for the energies in Table 6 are the differences of the $\mathrm{E}_{\mathrm{o}}$ 's and not the ZPE and thermally corrected values in Tables 2 and 5. Also, these geometries are not optimized but just torsional rotations about the HB. The values in parenthesis are the values reported in the Guillaumes and Simon paper. The differences in values are attributable to the differences in the particular implementations of B3LYP in the Gaussian 03 program and B3LYPV3 in GAMESS. Notably, the absolute values of each set of calculations are not significantly different regardless of the DFT method utilized.

Table 6. Values of the Ring Reorganization energy are computed by GAMESS: B3LYP3V/6-311++G**

\begin{tabular}{|c|c|c|c|c|c|}
\hline${ }^{a}$ ERiR $(\mathrm{kJ} / \mathrm{mol})$ & -lactam & -lactam-3-ene & -lactam-4-ene & Oxindole & Isoxindole \\
\hline SHBD-90 & $-40 .{ }^{\mathrm{b}}(-22)$. & $-44.7(-23.4)$ & $-42.3(-20.9)$ & -41.0 & -43.5 \\
\hline SHBD-180 & -23.0 & -22.0 & -23.8 & -23.0 & -23.0 \\
\hline
\end{tabular}

${ }^{\mathrm{a}} \mathrm{E}_{\text {RiR }}=$ Ring Reorganization energy[15] ; ${ }^{\mathrm{b}}$ values in parenthesis from reference 15. 
Although the $\gamma$-lactam-3-ene SHBD-180 (Figure 9a) and Isoxindole SHBD- $180^{\circ}$ (Figure 10a) structures have $\mathrm{C}_{\mathrm{s}}$ symmetry, one important difference between them is that the aromatic ring in Isoxindole is in a position that blocks the access to the other five membered ring due to the $\mathrm{C}=\mathrm{O}---\mathrm{H}-\mathrm{C}$ HB interaction.

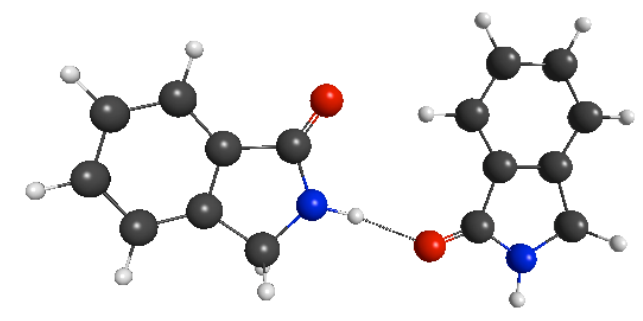

Figure 10a. Isoxindole SHBD-180

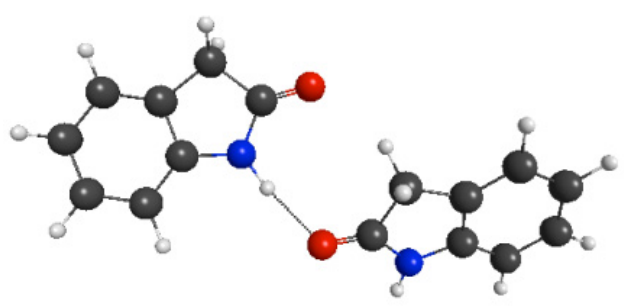

Figure 10b. Oxindole SHBD- $180^{\circ}$

Our research finds that regardless of the level of theory used in the calculations there is a general feature of the difference in the electron densities between the monomer and dimer for each of the three compounds that is directly related to the enthalpy of dimerization and the size of their equilibrium constants. Electrostatic potential maps of all three compounds (Figures 11a, 11b and 11c) show where the electron density shifts when going from monomer to dimer. The color ordering from highest to lowest electrostatic potential is red, orange, yellow, green, light blue and dark blue. The region of high electron density persists as a darker red in both the monomer and dimer where the oxygens are located. The dimer formation of Oxindole reveals the lowest electrostatic potential away from the carbonyl oxygen into the aromatic ring. The Isoxindole electrostatic map reveals very little electron shifting from the carbonyl oxygen to the aromatic ring. The primary difference between Oxindole and Isoxindole is the conjugation of the aromatic ring with the amide $\mathrm{N}$ or the amide $\mathrm{C}=\mathrm{O}$, respectively. Isoxindole has the $\mathrm{C}=\mathrm{O}$ of the amide in conjugation with the aromatic ring and the hydrogen-bonding of the dimer is enhanced relative to the saturated ring of $\gamma$-lactam. When the nitrogen of the amide is in conjugation with the aromatic ring, the effect on strength of hydrogen-bonding is decreased relative to the saturated ring of the $\gamma$-lactam. The experimentally determined ordering of the magnitudes of $\Delta \mathrm{H}_{\mathrm{d}}$ for these three compounds is corroborated by computation.

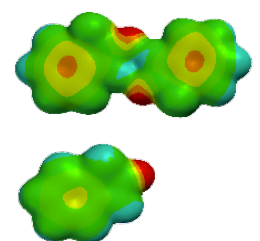

11a. Oxindole

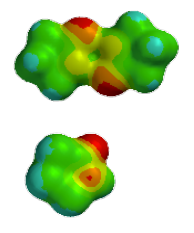

$11 \mathrm{~b} \gamma$-lactam

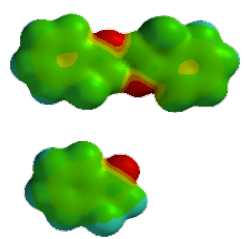

11c Isoxindole
Figure 11. Electrostatic potential maps in increasing magnitude of HB strength and concentration of electrostatic potential at the carbonyl oxygen.

\section{Discussion and Conclusion}

At the outset of this investigation, the intention of this research was to investigate the effect of conjugation on the HB strength of a multiply hydrogen-bonding system. Past research of lactams has served to elucidate the effects of ring size on the strength and relative amounts of multiple hydrogen-bonding. The small size of these molecules makes these systems computationally economical. The saturated $\gamma$-lactam, was found to be an optimum benchmark compound for the Oxindole and Isoxindole moieties. The $\gamma$-lactam benchmark demonstrates that creating conjugation with the nitrogen in Oxindole increases the $\Delta \mathrm{H}_{\mathrm{d}}$ and decreases the degree of association of five-membered lactam rings. The best agreement between theory and experiment for the spectroscopic parameters $\Delta v$, $\varepsilon_{\mathrm{d}} / \varepsilon_{\mathrm{m}}$ and trends of $\Delta \mathrm{H}_{\mathrm{d}}$ occurred with the B3LYP/6-31G** combination of method and basis set accompanied by the PCM method of incorporating a dielectric effect of the solvent, $\mathrm{CCl}_{4}$.

Two new experimental methods are introduced in this project. One method is the linear least-squares fitting of the computed spectra determination of the scaling between the assigned and computed IR frequencies. Rather than using a single multiplicative scaling factor to scale the computed high frequency peaks, this method corrects the zero intercept assumption by utilizing as many high frequency peaks within several hundred $\mathrm{cm}^{-1}$ of each other. The other method is the use of the monomer and dimer $\mathrm{N}-\mathrm{H}$ stretching frequencies to evaluate two parameters, $\varepsilon_{\mathrm{d}} / \varepsilon_{\mathrm{m}}$ and $\mathrm{K}_{\mathrm{d}}$. This involved the use of the Simplex algorithm because of the non-linear equation $\mathbf{5}$ used in relating the ratio $A_{d} / A_{m}$ to $C_{T}$. The overlapping interference of the dimer peak with other spectral features was obviated by the symmetry of the dimer peak. Fitting the peaks in the 2800 to the $3500 \mathrm{~cm}^{-1}$ range with Gaussian and Lorentzian peaks indicated that the dimer peak is very nearly $100 \%$ Lorentzian. This suggests either a predissociative or dephasing mechanism for the disruption of the HB. The energy of the fundamental frequency of the dimer $\mathrm{N}-\mathrm{H}$ (asymmetric) stretch is greater in energy than the $\Delta \mathrm{H}_{\mathrm{d}}$ of the dimer, which suggests the predissociative mechanism. 
The unexpected destabilization of the HB of Oxindole relative to $\gamma$-lactam is accounted for by comparing the changes between the monomer and dimer electrostatic potential maps of all three compounds. The electrostatic potential map of Isoxindole shows a relative shift of electron density into the hydrogen-bonding region of the dimer relative to the monomer. This shift comes at the expense of the electron density from the conjugated $\pi$ system of the attached aromatic ring. Comparing the electrostatic map of the $\gamma$-lactam monomer with the dimer show no notable shifting of electron density and there is a large amount of electron density in the region of the HB in both cases. Finally, a comparison of the Oxindole electrostatic maps of monomer and dimer show a significant shift in electron density into the aromatic ring structure upon formation of the dimer.

The role of the solvent dielectric is most pronounced in computing the $\varepsilon_{\mathrm{m}}$ for the $\mathrm{N}-\mathrm{H}$ monomer frequency and $\varepsilon_{\mathrm{d}}$ for the $\mathrm{N}-\mathrm{H}$ dimer frequency with and without dielectric effects. When the solvent dielectric is turned on, the $\varepsilon_{\mathrm{m}}$ is roughly doubled, but the $\varepsilon_{\mathrm{d}}$ is essentially the same. This response to the dielectric makes sense when one considers the idea behind the Self Consistent Reaction Field (SCRF) model of PCM. The original electron density of the molecule will most be affected in polar regions of the molecule which are exposed to the polarizing effect of the solvent. The solvent in response to the new polarization of the molecule will change the dielectric in the region of the molecule. As a result, the electron density of the solute will again shift and so on until the induced difference between the polarity of the molecule and the polarizing effect of the solvent have become self consistent. The exposed polar end of the monomer is going to require a larger response to the solvent than the shielding afforded by the two polar ends joining in a $\mathrm{C}_{2}$ (or $\mathrm{C}_{\mathrm{i}}$ ) symmetry of the dimer.

In addition to the spectral and computational results, the lower solubility of Isoxindole is consistent with the higher enthalpy of dimerization and the larger equilibrium constant relative to Oxindole. The primary effect for lower solubility is better crystal packing in conjunction with stronger intermolecular forces.

The conclusions of the Gilli and Gilli[32] and Guerra, et. al.[33] research of the hydrogen-bond theory is reinforced by this work. The primary effect according their research is that the reorganization of electron density of the two monomer units via the formation of a dimer is the major contribution to the stability of the HB. Our research further develops the mechanism for the enhancement of stability of the HB of Isoxindole relative to $\gamma$-lactam due to the polarizing effect on the monomer produced by the dielectric of the non-polar solvent, $\mathrm{CCl}_{4}$. The conjugation effect with the lactam $\mathrm{C}=\mathrm{O}$, is responsible for electron density migration into the HB region. In addition, conjugation with the lactam nitrogen is not effective in shifting electron density to the region of the HB. The inferences of our computational results are solidly in line with the experimental results giving further credence to our computational results and interpretation.

\section{Acknowledgements}

The authors of this paper would like to thank the Butler University Supercomputing facility for allowing us to execute the GAMESS program on the Thomas node. The authors would also like to thank Dr. P. Morgan, Dr. A. Azman and Dr. J. Esteb for their insightful comments in the preparation of this paper. Special thanks must go to Dr. V. J. Klimkowski for his many hours spent helping to revise the original drafts of this paper and his insights for clarification of the interpretation of the results. The authors would also like to acknowledge the Holcomb Awards Committee for funding of the Starna Infrasil ${ }^{\circledR}$ cell and capital funds generated by Frank Levinson Foundation for the funding of the workstations and Gaussian 03 program.

\section{REFERENCES}

[1] Sullivan, L. The Autobiography of an Idea. Dover Publications: New York, 1956.

[2] Pauling, L. The Nature of the Chemical Bond. $3^{\text {rd }}$ Ed. Cornell University Press, Cornell University, 1960.

[3] Lehninger, A; Nelson, D. A.; Cox, M. M. Lehninger Principes of Biochemistry, Fifth Edition. W. H. Freeman \& Company, New York, 2008.

[4] Politzer, P.; Murray, J. S.; Clark, T., Mathematical modeling and physical reality in noncovalent interactions, J. Mol. Model, 2015, 21, 52.

[5] Klein, C. L.; Stevens, E. D. In:Liebman, J. F.; Greenberg, A. (eds) Structure and Reactivity. VCH, New York, 1988, pp 25-64.

[6] Adler, M.; Laughlin, B.; Lieb, S. G., Effects of lactam ring size on the thermodynamics of hydrogenbonding in $\mathrm{CCl} 4$ solutions : experimental and ab initio studies, Phys. Chem. Chem. Phys., 1999, 1, 5333 - 5338.

[7] Chen, C. Y. S.; Swenson, C. A., Self association of some lactams, J. Phys. Chem. 1969, 73, 1363 - 1366.

[8] Wamsley, J. A., An investigation of the self-association of 2-prrolidinone in cyclohexane and carbon tetrachloride by means of spectroscopic and dielectric polarization measurements, J. Phys. Chem. 1976, 80, 2745 - 2753.

[9] Walmsley, J. A., Self-association of 2-Pyrrolidinone. 2. Spectral and Dielectric Polarization Studies of Benzene Solutions, J. Phys. Chem. 1978, 18, 2031 - 2035.

[10] Krikorian, S. E., Determination of dimerization constants of cis- and trans-configured secondary amides using near-infrared spectroscopy, J. Phys. Chem. 1982, 86, 1875 1881. 
[11] Prokopenko, N. A.; Bethea, I. A.; Clemens, C. J.; Klimek, A.; Wargo, K.; Spivey, C.; Waziri, K.; Grushow, A., The effect of structure on hydrogen bonding: Hydrogen bonded lactams in $\mathrm{CCl}_{4}, P C C P, 2002,4,490$ - 495.

[12] Yekeler, H., Solvent effects on dimeric self-association of 2-pyrrolindone: an ab inito study, J. Comp-Aid. Mol. Des., 2001, 15, $287-295$.

[13] Baker, J.; Sifniades, S., Synthesis and Properties of Pyrrolin-2-ones, J. Org. Chem. 1979, 44, 2798-2800.

[14] Koll, A.; Rospenk, M., Study of the association of 2-oxoindolines in carbon tetrachloride solutions by IR spectra, dipole moments and average molecular weight measurements, J. Phys. Org. Chem., 7, 171 - 177.

[15] Guillaumes, L.; Simon, S., Dealing with Quasi-Ring Formation by Two Hydrogen Bonds. Cooperativity Analysis and Delocalization Indices, J. Phys. Chem. A, 2014, 118, 9727 - 9733.

[16] Guillaumes, L.; Simon, S.; Guerra, C. F., The Role of Aromaticity, Hybridization, Electrostatics, and Covalency in the Resonance-Assisted Hydrogen Bonds Adenine-Thymine (AT) Base Pairs and Their Mimics, ChemistryOpen, 2015, 4, 318 - 327.

[17] Palusiak, M.; Simon, S.; Sola, M., Interplay between Intramolecular Resonance-Assisted Hydrogen Bonding and Aromaticity in O-Hydroxyaryl Aldehydes. J. Org. Chem., 2006, 71, 5241 - 5248.

[18] Palusiak, M.; Simon, S.; Sola, M., Interplay between Intramolecular Resonance-Assisted Hydrogen Bonding and Local Aromaticity. II. 1,3-Dihydroxyaryl-2-aldehydes, J. Org. Chem., 2009, 74 (5), 2059 - 2066.

[19] Palusiak, M.; Simon, S.; Sola, M., The Proton Transfer Reaction in Malonaldehyde Derivatives: Substituent Effects and Quasi-Aromaticity of the Proton Bridge. Chem. Phys., 2007, 342, 43 - 54.

[20] Grabowski, S.; Dubis, A.; Martynowski, D.; Główka, M.; Palusiak, M.; Leszczynski, J., Crystal and Molecular Structure of Pyrrole-2-carboxylic Acid; -Electron Delocalization of Its Dimers-DFT and MP2 Calculations, J. Phys. Chem. A, 2004, 108, 5815 -5822 .

[21] Gaussian 03, Revision E.01, Frisch, M. J.; Trucks, G. W.; Schlegel, H. B.; Scuseria, G. E.; Robb, M. A.; Cheeseman, J. R.; Montgomery, Jr., J. A.; Vreven, T.; Kudin, K. N.; Burant, J. C.; Millam, J. M.; Iyengar, S. S.; Tomasi, J.; Barone, V.; Mennucci, B.; Cossi, M.; Scalmani, G.; Rega, N.; Petersson, G. A.; Nakatsuji, H.; Hada, M.; Ehara, M.; Toyota, K.; Fukuda, R.; Hasegawa, J.; Ishida, M.; Nakajima, T.; Honda, Y.; Kitao, O.; Nakai, H.; Klene, M.; Li, X.; Knox, J. E.; Hratchian, H. P.; Cross, J. B.; Bakken, V.; Adamo, C.; Jaramillo, J.; Gomperts, R.; Stratmann, R. E.; Yazyev, O.; Austin, A. J.; Cammi, R.; Pomelli, C.; Ochterski, J. W.; Ayala, P. Y.; Morokuma, K.; Voth, G. A.; Salvador, P.; Dannenberg, J. J.; Zakrzewski, V. G.; Dapprich, S.; Daniels, A. D.; Strain, M. C.; Farkas, O.; Malick, D. K.; Rabuck, A. D.; Raghavachari, K.; Foresman, J. B.; Ortiz, J. V.; Cui, Q.; Baboul, A. G.; Clifford, S.;
Cioslowski, J.; Stefanov, B. B.; Liu, G.; Liashenko, A.; Piskorz, P.; Komaromi, I.; Martin, R. L.; Fox, D. J.; Keith, T.; Al-Laham, M. A.; Peng, C. Y.; Nanayakkara, A.; Challacombe, M.; Gill, P. M. W.; Johnson, B.; Chen, W.; Wong, M. W.; Gonzalez, C.; and Pople, J. A.; Gaussian, Inc., Wallingford CT, 2004. Gaussian 03, Revision C.02, Gaussian Inc., Wallingford, CT 2004.

[22] Schmidt, M.W.; Baldridge, K.K.; Boatz, J.A.; Elbert, S.T.; Gordon, M.S.; Jensen, J.H.; Koseki, S.; Matsunaga, N.; Nguyen, K.A.; Su, S.J.; Windus, T.L.; Dupuis, M.; Montgomery, General atomic and molecular electronic structure system, J. Comput. Chem, 1993, 14 (11), 1347 1363.

[23] Johnson III, R. D.; Irikura, K. K.; Kacker, R. N.; Kessel, R., Scaling Factors and Uncertainties for ab Initio Anharmonic Vibrational Frequencies, J. Chem. Theory Comput. 2010, 6, 2822 - 2828.

[24] Hachuła, B.; Zerzucha, P.; Zubko, M.; Kusz, J., 6-Chloro-2oxindole: X-ray and DFT-calculated study, Acta Crystallogr C, 2011, 67, o413-o416.

[25] Pandey, P.; Samanta, A.; Bandyopadhyay, B.; Chakraborty, T., Infrared spectroscopy of 2-pyrrolidinone and its cold (8 K) inert gas matrix Vib. Spect. 2011, 55, 126 - 131.

[26] Pandey, P.; Samanta, A.; Bandyopadhyay, B.; Chakraborty, T., Amide-I and amide-A bands of d-valerolactam and its dimers: A combined matrix isolation - FTIR spectroscopy and quantum chemistry study, Journal of Molecular Structure, 2010, 975, 343 - 348.

[27] Flakus, H.; Hachuła, B., Polarized IR Spectra of the Hydrogen Bond in Two Different Oxindole Polymorphs with Cyclic Dimers in Their Lattices, J. Phys. Chem. A, 2011, 115, 12150 - 12160.

[28] Norskov-Lawritsen, L.; Burgi, H.-B.; Hofmann, P.; Schmidt, H. R., Helv. Chim. Acta, 1985, 68, 76.

[29] Lipkowski, J.; Luboradzki, R.; Stefaniak, L.; Wojcik, J., X-ray diffraction study of some indolinones, J. Chem. Cryst., 1995, 25, 299 - 308.

[30] Beck, J.; Mo, Y., How Resonance Assists Hydrogen Bonding Interactions: An Energy Decomposition Analysis, J. Comput. Chem., 2006, 28, 455 - 466.

[31] Sanz, P.; Yáñez, M.; Mó, O., Resonance Assisted Intrmolecular Chalcogen-Chalcogen Interactions, Chemistry - A European Journal, 2003, 9, 4548 - 4555.

[32] Gilli, G.; Gilli, P., Towards an Unified Hydrogen-Bond Theory J. Mol. Structure, 2000, 552, 1 - 15.

[33] Guerra, C. F.; Bickelhaupt, F. M.; Snijders, J. G.; Baerends, E., Ther Nature of the Hydrogen Bond in DNA Base Pairs: The Role of Charge Transfer and Resonace Assistance, Chem. - Eur. J., 1995, 5, 3581 - 3594.

[34] Asensio, A.; Kobko, N.; Dannenberg, J., Cooperative Hydrogen-Bonding in Adenine-Thymine and Guanine-Cytosine Base Pairs. Density Functional Theory and Møller-Plesset Molecular Orbital Study, J. Phys. Chem. A, 2003, 107, 6441 - 6443 . 